\title{
Study of the Atmospheric Chemistry of Radon Progeny in Laboratory and Real Indoor Atmospheres
}

Progress Report for the Period

July 1, 1992 to March 31, 1993

Philip K. Hopke

Department of Chemistry

Clarkson University

Potsdam, N.Y. 13699-5810

July 1992

\section{MASTER \\ APR 281993 \\ DISTRIBUTION OF THIS DOCUMENT IS UNLIMTIED}

$\mathrm{RLO}=i \mathrm{~B}$

Prepared for

THE U.S. DEPARTMENT OF ENERGY

AGREEMENT NO. DE-FG02-90ER61029

\section{DISCLAIMER}

This report was prepared as an account of work sponsored by an agency of the United States Government. Neitner the United States Government nor any agency thereof, nor any of their employees, makes any warranty, express or implied, or assumes any legal liability or responsibility for the accuracy, completeness, or usefulness of any information, apparatus, product, or process disclosed, or represents that its use would not infringe privately owned rights. Reference herein to any specific commercial product, process, or service by trade name, trademark, manufacturer, or otherwise does not necessarily constitute or imply its endorsement, recommendation, or favoring by the United States Government or any agency thereof. The views and opinions of authors expressed herein do not necessarily state or reflect those of the United States Government or any agency thereof. 


\begin{abstract}
This report covers 9 months of the third year of the current grant to Clarkson University to study the chemical and physical behavior of the ${ }^{218} \mathrm{Po}$ atom immediately following its formation by the alpha decay of radon. Because small changes in size for activity in the sub-10 nm size range result in large changes in the delivered dose per unit exposure, this behavior must be understood if the exposure to radon progeny and itsdose to the cells in the respiratory tract are to be fully assessed. In order to pursue this general goal, two areas of radon progeny behavior are being pursued; laboratory studies under controlled conditions to better understand the fundamental physical and chemical processes that affect the progeny's atmospheric behavior and studies in actual indoor environments to develop a better assessment of the exposure of the occupants of that space to the size and concentration of the indoor radioactive aerosol. Thus, two sets of specific goals have been established for this project.

The specific tasks of the controlled laboratory studies are 1.) Determine the formation rates of $\cdot \mathrm{OH}$ radicals formed by the radiolysis of air following radon decay, 2.) Examine the formation of particles by the radiolytic oxidation of substances like $\mathrm{SO}_{2}$, ethylene, and $\mathrm{H}_{2} \mathrm{~S}$ to lower vapor pressure compounds and determine the role of gas phase additives such as $\mathrm{H}_{2} \mathrm{O}$ and $\mathrm{NH}_{3}$ in determining the particle size, 3.) Measure the rate of ion-induced nucleation using a thermal diffusion cloud chamber, and 4.) Measure the neutralization rate of ${ }^{218} \mathrm{PoO}_{x}^{+}$in $\mathrm{O}_{2}$ at low radon concentrations.

The specific tasks of the exposure studies in occupied indoor spaces are 1.) Initiate measurements of the activity size distributions in actual homes with occupants present so that the variability of the indoor activity size distributions can be assessed with respect to indoor aerosol sources and general lifestyle variations of the occupants, 2.) Initiate a prospective study of the utility of measurement of deposited ${ }^{210} \mathrm{~Pb}$ embedded in glass surfaces as a measure of the long-term, integrated exposure of the population to radon, and 3.) Develop the methodology to determine the hygroscopicity of the indoor aerosol so that the changes in deposition efficiency of the radioactive indoor aerosol with hygroscopic growth in the respiratory tract can be assessed.
\end{abstract}

This report describes the progress toward achieving these objectives. 
LABORATORY STUDIES . OH Radical Production Rate $\ldots \ldots \ldots \ldots \ldots \ldots \ldots \ldots \ldots \ldots \ldots$

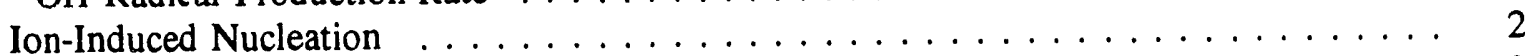

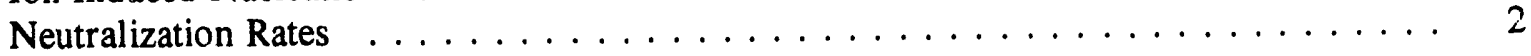

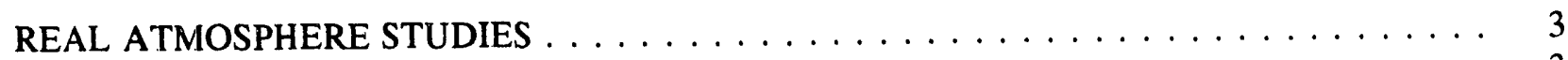

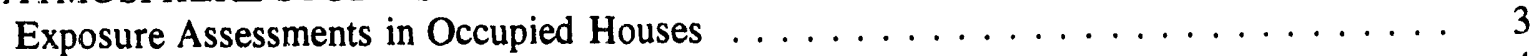

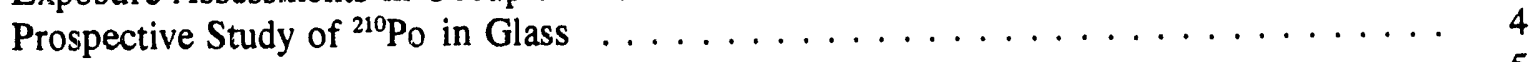

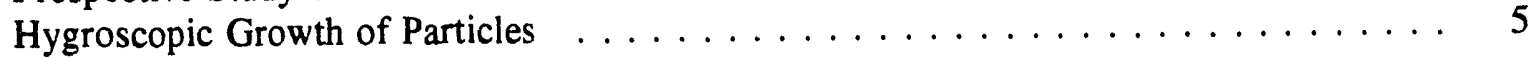

FUTURE RESEARCH PLANS $\ldots \ldots \ldots \ldots \ldots \ldots \ldots \ldots \ldots$

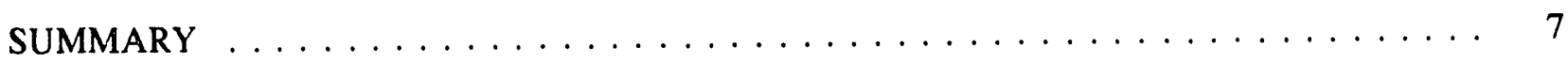

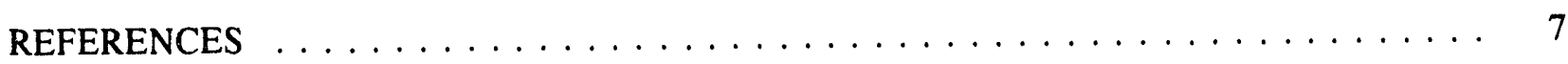

PROJECT PERSONNEL $\ldots \ldots \ldots \ldots \ldots \ldots \ldots \ldots \ldots \ldots \ldots$

PUBLICATIONS ARISING FROM THIS CONTRACT $\ldots \ldots \ldots \ldots \ldots \ldots \ldots$

PRESENTATIONS OF RESULTS OF THIS CONTRACT $\ldots \ldots \ldots \ldots \ldots \ldots$ 


\section{INTRODUCTION}

The health effects of the radon decay products are strongly dependent upon their behavior in the indoor atmosphere. Particularly for ${ }^{218} \mathrm{Po}$, the partitioning between the "unattached" state and the "attached" forms, combined with the preexisting aerosol particles, has a significant impact on the calculation of the dose to the lung resulting from a given decay product concentration. Thus, the chemical and physical behavior of the ${ }^{218} \mathrm{Po}$ atom immediately following its formation by the alpha decay of radon must be considered if its health implications are to be fully assessed. A discussion of the background to this problem has been presented in the previous year's report (Hopke, 1992).

\section{LABORATORY STUDIES}

The principal areas of the laboratory studies during the current period have been 1.) Determination of the formation rates of $\cdot \mathrm{OH}$ radicals formed by the radiolysis of air following radon decay, and 2.) Measurement of the rate of ion-induced nucleation using a thermal diffusion cloud chamber.

\section{OH Radical Production Rate}

We are measuring the hydroxyl radical concentrations produced from radon decay with two different ways. One approach uses the chemical amplification system developed by Cantrell et al. (1984). The other technique is direct measurement using a laser-induced fluorescence (LIF) system.

In the chemical amplifier system, $\cdot \mathrm{OH}$ radicals produced by ${ }^{222} \mathrm{Rn}$ decay in air participate in a series chain reactions with high concentrations of $\mathrm{CO}(10 \%)$ and $\mathrm{NO}(\mathrm{ppm})$, resulting in high concentrations of $\mathrm{NO}_{2}$. The product $\mathrm{NO}_{2}$ is measured by luminol chemiluminescence. These reactant gases as well as radon-laden $\mathrm{N}_{2}$ is mixed into a stream of purified air. The air then passes through a flow-through detector system based on the gas-surface reaction of $\mathrm{NO}_{2}$ with a $0.01 \mathrm{M} \mathrm{Na}_{2} \mathrm{SO}_{3}, 0.05 \%$ methanol, $0.001 \mathrm{M}$ aqueous luminol solution of $\mathrm{pH} 12$ (Maeda et al., 1980). Contaminant $\mathrm{NO}_{2}$ in the reactant $\mathrm{NO}$ gas is removed by passing the gas stream over $\mathrm{FeSO}_{4}$.

A manuscript describing the experiments was submitted to J. Atmospheric Chem. in October 1992. We received the reviews at the end of December. The reviewers raised some useful points about our work that have caused us to perform additional experiments to confirm that it is $\cdot \mathrm{OH}$ that is the active species and to better determine the chain length of our amplifier reaction sequence. These studies have been completed and a revised manuscript is about to be submitted to the journal 
which we are confident that it will be accepted (Ding and Hopke, 1993). We find that there are somewhat more $\cdot \mathrm{OH}$ radicals formed than ion-pairs yielding a G-value of $7.7 \pm 1.9 \cdot \mathrm{OH} / 100 \mathrm{eV}$.

A laser-induced fluorescence system was established using an excimer laser system. We determined the sensitivity of the system with $\cdot \mathrm{OH}$ produced by as high a radon concentration as we could put into the chamber. The response of the system was found to be insufficient to clearly observe a signal above the noise and thus, we have ceased further work on this aspect of the measurement.

\section{Ion-Induced Nucleation}

Another area of active development has been the construction of the thermal diffusion cloud chamber (TDCC) (Katz, 1970) to study the rates of ion-induced nucleation caused by the ions produced by the radon decay. Previously, we calculated that there is the possibility of ion-induced nucleation occurring for indoor volatile organic compounds (VOCs) at levels observed in indoor air (Daisey and Hopke, 1993). Thus, we currently making detailed studies of ion-induced nucleation of a series of VOCs. We wish to confirm the VOC calculations through direct measurement using the some of the specific compounds identified in our calculations. We have made some initial tests of the system using ${ }^{222} \mathrm{Rn}$ to produce the ions. However, the ionization produced by the $\alpha$ particle emitted by ${ }^{222} \mathrm{Rn}$ is columellar in nature. Thus, we want to make additional studies using the more diffuse ionization produced by the $B$ particle emitted by ${ }^{85} \mathrm{Kr} .{ }^{85} \mathrm{Kr}$ can be introduced into the chamber is very low concentrations. We are currently waiting for the ${ }^{85} \mathrm{Kr}$ to be delivered at which point those measurements will be made. Subsequently, we will complete the measurements with radon to determine its ability to induce nucleation.

Yefei Wu (1991) has theoretically investigated the behavior of the TDCC as his MS research problem. According to his calculations, we should be able to examine ion-induced of both VOCs and also the oxidation of $\mathrm{SO}_{2}$ /binary nucleation of $\mathrm{H}_{2} \mathrm{SO}_{4}-\mathrm{H}_{2} \mathrm{O}$ in the TDCC. These studies should be initiated during the next year.

\section{Neutralization Rates}

We have been corresponding with Professor A.J. Howard of the Department of Physics, Trinity College, Hartford, CT. Professor Howard has developed a system for measuring the neutralization rate for ${ }^{218} \mathrm{Po}^{+}$ions under well controlled conditions (Howard and Strange, 1991). He 
has obtained results in good agreement with our earlier measurements (Shi and Hopke, 1991). It appears that it may be easier to make the critical measurements of the $\mathrm{O}_{2}$ neutralization rates using their system. We are trying to plan for Dr Howard and his students to visit us in order to begin these experiments. Thus, the laboratory aspects of the project are underway and making good progress.

\section{REAL INDOOR ATMOSPHERE STUDIES}

The specific tasks of the exposure studies in occupied indoor spaces are 1.) Initiate measurements of the activity size distributions in actual homes with occupants present so that the variability of the indoor activity size distributions can be assessed with respect to indoor aerosol sources and general lifestyle variations of the occupants, 2.) Initiate a prospective study of the utility of measurement of deposited ${ }^{210} \mathrm{~Pb}$ embedded in glass surfaces as a measure of the long-term, integrated exposure of the population to radon, and 3.) Develop the methodology to determine the hygroscopicity of the indoor aerosol so that the changes in deposition efficiency of the radioactive indoor aerosol with hygroscopic growth in the respiratory tract can be assessed.

\section{Exposure Assessments in Occupied Houses}

The measurement of activity-weighted size distributions in normally occupied homes are made using the automated, semi-continuous, graded screen array system described by Ramamurthi and Hopke (1991). During the present period, we completed a series of measurements in a house in Gainesville, FL in January 1993. Another series of experiments were performed in a home in Princeton, NJ in March. During the Princeton exposure measurements, an additional set of intercomparison measurements were made in collaboration with personnel from the Environmental Measurements Laboratory. In our prior studies, there were differences in the estimated activity in the 1.5 to $15 \mathrm{~nm}$ size region. Although these differences do not appear significant in terms of typical aerosol measurements, they result in significant differences in estimated dose because of the very high dose per unit exposure in this size range. We are continuing to study the various approaches to the deconvolutions of the activity-weighted size distributions in order to understand the nature of the differences that have been seen. At this time, it is not clear why these differences exist and which results are correct.

Further studies in other homes are planned for the near-term future and we have a considerable amount of existing data from past studies that requires analysis and preparation of appropriate manuscripts. 


\section{Prospective Study of ${ }^{210} \mathrm{Po}$ in Glass}

Prior studies by Dr. R. Lively of the Minnesota Geological Survey (Lively and Ney, 1987) and Christer Samuelsson of Lund University, Sweden (Samuelsson, 1988) on the relationship between measured ${ }^{210} \mathrm{Po}$ embedded in glass and ambient radon concentrations. When ${ }^{214} \mathrm{~Pb}$ or ${ }^{214} \mathrm{Bi}$ is deposited on a surface in a room, they will adsorb to the surface. When the resulting ${ }^{214}$ Po emits its $\alpha$ particle, the ${ }^{210} \mathrm{~Pb}$ nucleus recoils with sufficient energy to embed it about $40 \mathrm{~nm}$ into the surface. Thus, it is thus below the surface and is not removed by cleaning, but it is close enough to the surface that the $5.3 \mathrm{MeV} \alpha$ from ${ }^{210}$ Po can be observed.

All of the previous work has been done using existing glass surface in the house and a year of $\alpha$ measurements. Lively and Steck (1991) has demonstrated the kind of wide variability that can occur even in the annual average radon concentration. Also people are not always certain when the particular piece of glass was placed into its current environment. Thus, some uncertainty exists in the value of the calibration constant. Furthermore, there has not been a study of the variations that might exist within a room or between rooms in the same house. These are the questions our study hopes to address.

Our study plan was to place 150 pairs of $8 " \times 10^{\prime \prime}$ pictures into houses. So far we have placed 144 pair of pictures into homes from California to New York. Another 20 pictures in groups of ten have been placed into two schools (one in Maine and the other in South Dakota). In 50 houses, the pictures are placed in the most lived in room of the house (living or family room). In 50 houses, the pair of pictures go in the master bedroom and in the remaining 50 houses, the pair are split between the two rooms. Within each group of 50 placed in the same room, we have split them into two groups. In the one case, both pictures are placed on an inside wall and in the other, the pair are split between inside wall and outside wall. For the 50 split between two rooms, half have both pictures on inside walls and half have both on outside walls. The pictures are being placed for 18 months. With each picture, there is at least one etched track detector. For 50 individual pictures chosen at random, there are 2 detectors as a QA check. We also have storage blanks and spiked samples.

In February 1993, we began the process of retrieve the exposed pictures. Each picture is individually wrapped in aluminum foil to prevent any inadvertent exposure in the laboratory. After an appropriate time to permit the ${ }^{210} \mathrm{Po}$ to come into secular equilibrium with the ${ }^{210} \mathrm{~Pb}$, we will count the activity in the glass with pulse ionization chambers for a sufficiently length of time to provide better than $10 \%$ counting statistics. In the meantime, the alpha track detectors are sent to the vendor 
to be counted. This study will give us a much tighter handle on the utility of this method for long term exposure assessment and therefore much improved epidemiology. However, several more years will be needed to complete this phase of our studies.

\section{Hygroscopic Growth of Particles}

The final task of this portion of the project was the development of the tandem differential mobility analyzer (TDMA) system to measure the hygroscopic growth of the indoor aerosol when it encounters $>99 \%$ relative humidity within the respiratory tract. A system has been developed that does permit the measurements to be made and a report describing this system has been published ( $\mathrm{Li}$ et al., 1992). The system has been used to perform a series of measurements on several types of indoor particle sources. Growth studies have been conducted on particles present in cigarette smoke (mainstream and sidestream), incense smoke, and produced by candles, natural gas and propane flames. The particles from cigarette smoke are introduced to first DMA right after they are generated from the burning tip. The aerosols from natural gas and propane gas flame are generated in a 55 gallon steel barrel and then introduced into the first DMA. The average residence time of aerosols in the barrel is about 4 minutes. The residence time of all aerosols in the humidifier is about 20 seconds, approximately equal to the residence time of aerosols in human's respiratory tract. These results were presented in the prior report (Hopke, 1992) and are in a manuscript that is being considered for publication in Aerosol Science \& Technology ( $\mathrm{Li}$ and Hopke, 1993). Additional studies of consumer products including hair spray, aerosol cleaning products, and pesticides have been performed and the results of these studies will be presented at the Indoor Air ' 93 conference in Helsinki in July 1993 (Hopke et al., 1993).

\section{FUTURE RESEARCH PLANS}

As of May 1, we will begin a new three year grant cycle. During this period, we will focus on completing the tasks describe above. With regards to laboratory studies, the $\cdot \mathrm{OH}$ radical production rates measurements have now been completed and we expect the graduate student, $\mathrm{H}$. Ding, to complete her degree program by the end of August 1993. It is clear from the results to date that radon decay will not produce a sufficient amount of $\cdot \mathrm{OH}$ to significantly affect indoor air chemistry at ${ }^{222} \mathrm{Rn}$ concentrations typically found in indoor air and thus, we do not anticipate any further studies in this area. 
The thermal diffusion cloud chamber is operating satisfactorily and measurements are in progress. Our initial work has been able to duplicate prior homogenous nucleation results on simple hydrocarbons thus insuring that the system is performing satisfactorily. We are examining the ioninduced nucleation of those organic compounds that had the highest free energy of formation in our calculations of ion-induced nucleation based on both the Suck (1982) and Thompson (1906) theories. Since there are discrepancies between the two theories, the quantitative measurements of the nucleation rates that we will be able to make could help to resolve the discrepancies as well as add to the data base for future theoretical studies. Ultimately, we plan to look at the combined oxidation and nucleation mechanism to study the binary nucleation of water and sulfuric acid.

In our field studies, we have tested the first pulse ionization chamber. We have acquired the counting electronics to allow us to build 6 additional units so that we can efficiently count the glass when the ${ }^{210} \mathrm{Po}$ has adequately grown into secular equilibrium with the ${ }^{210} \mathrm{~Pb}$. As the counters come on-line, we will be looking for opportunities to use the counters to measure artifacts in conjunction with on-going epidemiological studies. We hope to be able to begin taking data that can subsequently be fully evaluated when our prospective glass study has been completed.

We continue to find houses in which we can make exposure measurements. It appears that we will have additional houses to study during the next year in which we will measure activity size distributions in a series of normally occupied homes. We would like a mixture of various housing conditions (oil versus gas heating, hot water versus forced air, gas versus electric stoves, absence or presence of wood stove or fireplases, use of space heaters (electric or kerosene), presence or absence of electrostatic air cleaners and/or humidifier on forced air systems, and effects of central air conditioning). In addition to the activity size distributions, we also plan to measure particle number distributions with the DMA and we hope to be able to measure deposition flux so that the room surface-to-volume ratio can be inferred. These additional measurements are by nature grab measurements, but they can provide the data to estimate the room model parameters necessary to better understand the dynamics of the radon progeny in the house.

We are continuing to use the TDMA system to measure the hygroscopic growth of particles from a number of specific sources. The system is not readily portable. The need for several water baths to produce the temperature-controlled water for the wet-film reactor and for the bubblers used to temperature condition and humidify the sheath air for the second DMA means we will have to study aerosols in the laboratory and a very limited range of houses. We want to make additional laboratory studies of sources like a kerosene heater, and electric motors similar to those found in 
vacuum cleaners. We also plan to examine addition aerosol-spray products including spray deodorant, PAM spray-on oil, household deodorizer (such as Lysol or Glade air freshener), and additional pesticide sprays.

We will move the system to Professor Hopke's home for additional studies of a free standing wood stove (Vermont Casting Model "Resolute"), an open fireplace, an electric broiler cooking meat (Jenn-Aire broiler), a deep-fat fryer, and background aerosol at several times during the year. We will also examine the particles in the presence of a number of people in the room to examine people as an aerosol source.

\section{SUMMARY}

We made continuing progress based on our previous efforts. All of the experimental systems are now on-line, and we are well into the collection of substantial new data characterizing the behavior of the radon progeny both in the laboratory and in the real world.

\section{REFERENCES}

Cantrell, C.A., Stedman, D.H., and Wendel, G.J. (1984) Measurement of Atmospheric Peroxy Radicals by Chemical Amplification, Anal. Chem. 56:1496-1502.

Daisey, J.M. and P.K. Hopke (1993) Potential for Forming Ultrafine Aerosols from Indoor Organic Vapors by Radon Decay Radiolysis-Induced Reactions, Aerosol Sci. Technol. (in press).

Ding, H. and P.K. Hopke (1993) OH Production Due to Radon Decay in Air, J. Atmospheric Chem. (Submitted October 1992; Revised Version April 1993).

Hopke, P.K. (1992) Study of the Atmospheric Chemistry of Radon Progeny in Laboratory and Real Indoor Atmospheres, Progress Report for the Period July 1, 1991 to June 30, 1992, U.S > Department of Energy Report DOE/ER/61029-9.

Hopke, P.K., W. Li, and S.K. Dua (1993) Hygroscopic Growth of Particles from Indoor Sources, presented at the Sixth International Conference on Indoor Air Quality and Climate, Helsinki, Finland, July 4-8, 1993.

Howard, A.J. and W.P. Strange (1991) Measurement of ${ }^{218} \mathrm{Po}^{+}$Neutralization Rates in Gases, Nucl. Instrum. Methods A311:378-385.

Katz, J.L. (1970) Condensation of a Supersaturated Vapor, I. The Homogeneous Nucleation of the nAlkanes, J. Chem. Phys. 52:4733-4748.

Li, W. and P.K. Hopke (1993) Initial Size Distributions and Hygroscopicity of Indoor Combustion Aerosol Particles, Aerosol Sci. Technol. (in press). 
Li, W., N. Montassier and P.K. Hopke (1992) A System to Measure the Hygroscopicity of Aerosol Particles, Aerosol Sci. Technol. 17:25-35.

Lively, R. and E.P. Ney (1987) Surface Radioactivity Resulting from the Deposition of 222Rn Daughter Products, Health Phys. 52:411-415.

Lively, R. and D. Steck (1991) Current Status of Glass as a Retrospective Radon Monitor, in the Proceedings of the 1991 Symposium on Radon and Radon Reduction Technology, U.S.Environmental Protection Agency, Research Triangle Park, NC.

Maeda, Y.K., K. Aoki, and M. Munemori (1980) Chemiluminescence Method for the Determination of Nitrogen Dioxide, Anal. Chem. 52:307-311.

Ramamurthi, M. and P.K. Hopke (1991) An Automated, Semi-Continuous System for Measuring Indoor Radon Progeny Activity-Weighted Size Distributions, $\mathrm{d}_{\mathrm{p}}$ : 0.5-500 nm, Aerosol Sci. Technol. 14:82-92.

Samuelsson, C. (1988) Retrospective Determination of Radon in Houses, Nature 334:338-340

Shi, B. and P.K. Hopke, (1991) The Study of Neutralization of Po-218 Ions by Small Ion Recombination in $\mathrm{O}_{2}$, Ar and $\mathrm{N}_{2}$, Health Phys. 61:209-214.

Suck, S.H. (1982) Change of Free Energy in Heteromolecular Nucleation: Electrostatic Energy Contribution, J. Chem. Phys. 75:5090-5096

Thompson, J.J. (1906) Conduction of Electricity Through Gases, Cambridge University Press, London

Wu, Y. (1991) Using the Thermal Diffusion Cloud Chamber to Study the Ion-Induced Nucleation by Radon Decay, MS Thesis, U.S. Department of Energy Report No. DE/ER/61029-7.

\section{CURRENT PROJECT PERSONNEL}

Principle Investigator

Philip K. Hopke, Robert A. Plane Professor of Chemistry

Other Professionals Nathalie Montassier, Research Associate, August 1, 1990 - July 31, 1992

Graduate Research Assistants

Huiling Ding, Research Assistant, July 1, 1990 - present.

Wei Li, Research Assistant, July 1, 1990 - present.

Feng He, Research Assistant, August 15, 1991 - present. 


\section{PUBLICATIONS ARISING FROM THIS CONTRACT}

Measurement of the Size Distributions of Radon Progeny in Indoor Air, P.K. Hopke, M.

Ramamurthi, and C.S. Li, in Aerosols: Science, Industry, Health, and Environment, S. Masuda and K. Takahashi, eds, Vol. 2, Pergamon Press, Ltd, Oxford, $842-847$ (1990).

The Effect of Air Cleaning on the Size of the Radioactive Indoor Aerosol, P.K. Hopke, C.S. Li, and M. Ramamurthi, in Aerosols: Science, Industry, Health, and Environment, S. Masuda and K. Takahashi, eds, Vol. 2, Pergamon Press, Ltd, Oxford, 827-832 (1990).

Field Evaluation and Health Assessment of Air Cleaners in Removing Radon Decay Products in Domestic Environments, C.S. Li, Ph.D. thesis, University of Illinois at Urbana-Champaign, Urbana, IL, Department of Energy Report No. DOE ER61029-2, (1990).

Radon and Radon Progeny Measurements, P.K. Hopke and P. Wasiolek, Trends Anal. Chem. 10:243-249 (1991).

Intercomparison of Activity Size Distribution Measurements with Manual and Automated Diffusion Batteries - Field Test, P.K. Hopke, P. Wasiolek, E.O. Knutson, C. Gogolak, A. Cavallo, K. Gadsby and D. Van Cleef, in the Proceedings of the 1991 International Symposium on Radon and Radon Reduction Technology, Philadelphia, PA, U.S. Environmental Protection Agency, Research Triangle Park, NC, 1991.

Analysis of the Performance of the Radon Mitigation System Based on Charcoal Bed, P. Wasiolek, N. Montassier, P.K. Hopke and R. Abrams, in the Proceedings of the 1991 International Symposium on Radon and Radon Reduction Technology, Philadelphia, PA, U.S. Environmental Protection Agency, Research Triangle Park, NC, 1991.

The Field Measurements of the Activity-Weighted Size Distribution of Radon Decay Products, P. Wasiolek, P.K. Hopke, N. Montassier, A. Cavallo and K. Gadsby, in Measurement of Toxic and Relaied Air Pollutants, B. Gay and R.K.M. Jayanty, eds., Air \& Waste Management Association, Pittsburgh, PA, 128-133, 1991.

The Effect: of Air Cleaners on the Indoor Radon Hazard, C.S. Li, and P.K. Hopke, Paper No. 9163.2, Air \& Waste Management Association, Pittsburgh, PA, 1991.

Using the Thermal Diffusion Cloud Chamber to Study the Ion-Induced Nucleation by Radon Decay, MS Thesis, DOE Report No. DE/ER/61029-7 (1991).

The Production of Sulfate Particles Through the Radiolytic Oxidation of Sulfur Dioxide, K. KarpenHayes, MS Thesis, DOE Report No. DE/ER/61029.8 (1991).

The Study of Neutralization of Po-218 Ions by Small lon Recombination in $\mathrm{O}_{2}$, Ar and $\mathrm{N}_{2}$, B. Shi and P.K. Hopke, Health Physics 61:209-214 (1991).

The Efficacy of Air Cleaning Systems in Controlling Indoor Radon Decay Products, C.S. Li and P.K. Hopke, Health Physics 61:785-797 (1991). 
Measurement of Size Distributions of Indoor Radioactive Aerosol, C.S. Li and P.K. Hopke, in Indoor Radon and Lung Cancer: Myth or Reality, Battelle Memorial Press, Columbus, OH, 113-128 (1992).

Air Cleaning and Radon Decay Product Mitigation, P.K. Hopke, C.S. Li, and M. Ramamurthi, in Indoor Radon and Lung Cancer: Myth or Reality, Battelle Memorial Press, Columbus, OH, 479-491 (1992).

Some Thoughts on the "Unattached" Fraction of Radon Decay Products, P.K. Hopke, Health Phys. 63 2:209-212 (1992).

Measurement of the Effect of $\mathrm{SO}_{2}$ on the Polonium-218 Ion Mobility Spectrum by Alpha-Track Detection, S.C. Yoon, W.H. Marlow and P.K. Hopke, Health Physics 62:51-57 (1992).

Characterization of Radon Decay Products in the Domestic Environment, C.S. Li and P.K. Hopke, Indoor Air 4:539-561 (1992).

Inconsistency in the Length of a Working Month, P.K. Hopke and N. Montassier, Health Phys. 63:466-467 (1992).

Inspiratory Deposition of Ultrafine Particles in Human Nasal Replicate Models, D.L. Swift, N. Montassier, P.K. Hopke, K. Karpen-Hayes, Y.-S. Cheng, Y.F. Su, H.C. Yeh and J.C. Strong, J. Aerosol Science 23:65-72 (1992).

A System to Measure the Hygroscopicity of Aerosol Particles, W. Li, N. Montassier and P.K. Hopke, Aerosol Sci. Technol. 17:25-35 (1992).

Assessment of Exposure to Radon Decay Products in Realistic Living Conditions, P.T. Wasiolek, P.K. Hopke and A.C. James, J. Exposure Anal. Environ. Epidemiology 2:309-322 (1992).

The Measurement of Activity-Weighted Size Distribution of Radon Progeny: Methods and Laboratory Intercomparison Studies, P.K. Hopke, M. Ramamurthi, E.O. Knutson, K.W. Tu, P. Scofield, R.F. Holub, Y.S. Cheng, Y.F. Su, W. Winklmayr, J.C. Strong, S. Solomon, and A. Reineking, Health Phys. 63 5:560-570 (1992).

Penetration of Ultrafine Particles of ${ }^{218}$ Po Through Human Nasal and Oral Cast Models, N.

Montassier, K. Karpen-Hayes, P.K. Hopke and D.L. Swift, Rad. Prot. Dosim. 45:665-667 (1992).

easurement of Activity-Weighted Size Distributions of Radon Decay Products in Normally Occupied Homes, P.K. Hopke, P. Wasiolek, N. Montassier, A. Cavallo, K. Gadsby and R. Socolow, Rad. Prot. Dosim. (in press, 1993).

Nanometer and Ultrafine Aerosols from Radon Radiolysis, M. Ramamurthi, R. Strydom and P.K. Hopke, J. Aerosol Sci. (in press 1993).

Potential for Ion-Induced Nucleation of Volatile Organic Compounds by Radon Decay in Indoor Environments, J.M. Daisey and P.K. Hopke, Aerosol Sci. Technol. (in press, 1993). 
Analysis of the Performance of a Radon Mitigation System Based on Charcoal Beds, P. Wasiolek, N. Montassier, P.K. Hopke, R. Abrams, Environmental Technology Letters (in press, 1993).

Initial Size Distributions and Hygroscipicity of Indoor Combustion Aerosol Particles, W. Li and P.K. Hopke, Aerosol Sci. Technol. (in press, 1993).

Evaluation of the Effectiveness of Several Air Cleaners for Reducing the Hazard from Indoor Radon Progeny, P.K. Hopke, N. Montassier, and P. Wasiolek, Aerosol Sci. Technol. (in press, 1993).

\section{PRESENTATIONS OF RESULTS OF THIS CONTRACT}

Measurement of the Size Distributions of Radon Progeny in Indoor Air, P.K. Hopke, M. Ramamurthi and C.S. Li, presented at Third International Aerosol Conference, Kyoto, Japan, September 1990.

The Effect of Air Cleaning on the Size of the Indoor Radioactive Aerosol, P.K. Hopke, C.S. Li, and M. Ramamurthi, presented at Third International Aerosol Conference, Kyoto, Japan, September 1990.

Air Cleaning and Radon Decay Product Mitigation, P.K. Hopke, C.S. Li, and M. Ramamurthi, presented to the 29th Hanford Symposium on Health and the Environment, Richland, WA, October 1990.

Measurement of Size Distributions of Indoor Radioactive Aerosols, C.S. Li and P.K. Hopke, presented to the 29th Hanford Symposium on Health and the Environment, Richland, WA, October 1990.

Intercomparison of Activity Size Distribution Measurements with Manual and Automated Diffusion Batteries - Field Test, P.K. Hopke, P. Wasiolek, E.O. Knutson, C. Gogolak, A. Cavallo, K. Gadsby and D. Van Cleef, presented to the 1991 International Symposium on Radon and Radon Reduction Technology, Philadelphia, PA, 1991.

Analysis of the Performance of the Radon Mitigation System Based on Charcoal Bed, P. Wasiolek, N. Montassier, P.K. Hopke and R. Abrams, presented to the 1991 International Symposium on Radon and Radon Reduction Technology, Philadelphia, PA, 1991.

The Field Measurements of the Activity-Weighted Size Distributions of Radon Decay Products, P. Wasiolek, N. Montassier and P.K. Hopke, presented to the EPA/AWMA International Symposium on Measurement of Toxic and Related Air Pollutants, May 1991.

Penetration of Ultrafine Particles of ${ }^{218}$ Po Through Human Nasal and Oral Cast Models, $\mathrm{N}$. Montassier, K. Karpen-Hayes, P.K. Hopke, and D.L. Swift, presented at the Fifth International Symposium on the Natural Radiation Environment, Salzburg, September, 1991.

Measurement of Activity-Weighted Size Distributions of Radon Decay Products in Nornally Occupied Homes, P.K. Hopke, P. Wasiolek, N. Montassier, A. Cavallo, K. Gadsby and R. Socolow, presented at the Fifth International Symposium on the Natural Radiation Environment, Salzburg, September, 1991. 
Size Distributions of Radon Decay Products in Domestic Environments, P.K. Hopke and P. Wasiolek, presented at American Association for Aerosol Research, Traverse City, Michigan, October, 1991.

The Development and Testing of A System for the Determination of the Hygroscopic Growth of Aerosols, N. Montassier, W. Li and P.K. Hopke, presented at American Association for Aerosol Research, Traverse City, Michigan, October, 1991.

Hygroscopic Growth of Particles from Indoor Sources, P.K. Hopke, W, Li, and S.K. Dua, presented at the Sixth International Conference on Indoor Air Quality and Climate, Helsinki, Finland, Juıy 4-8, 1993. 

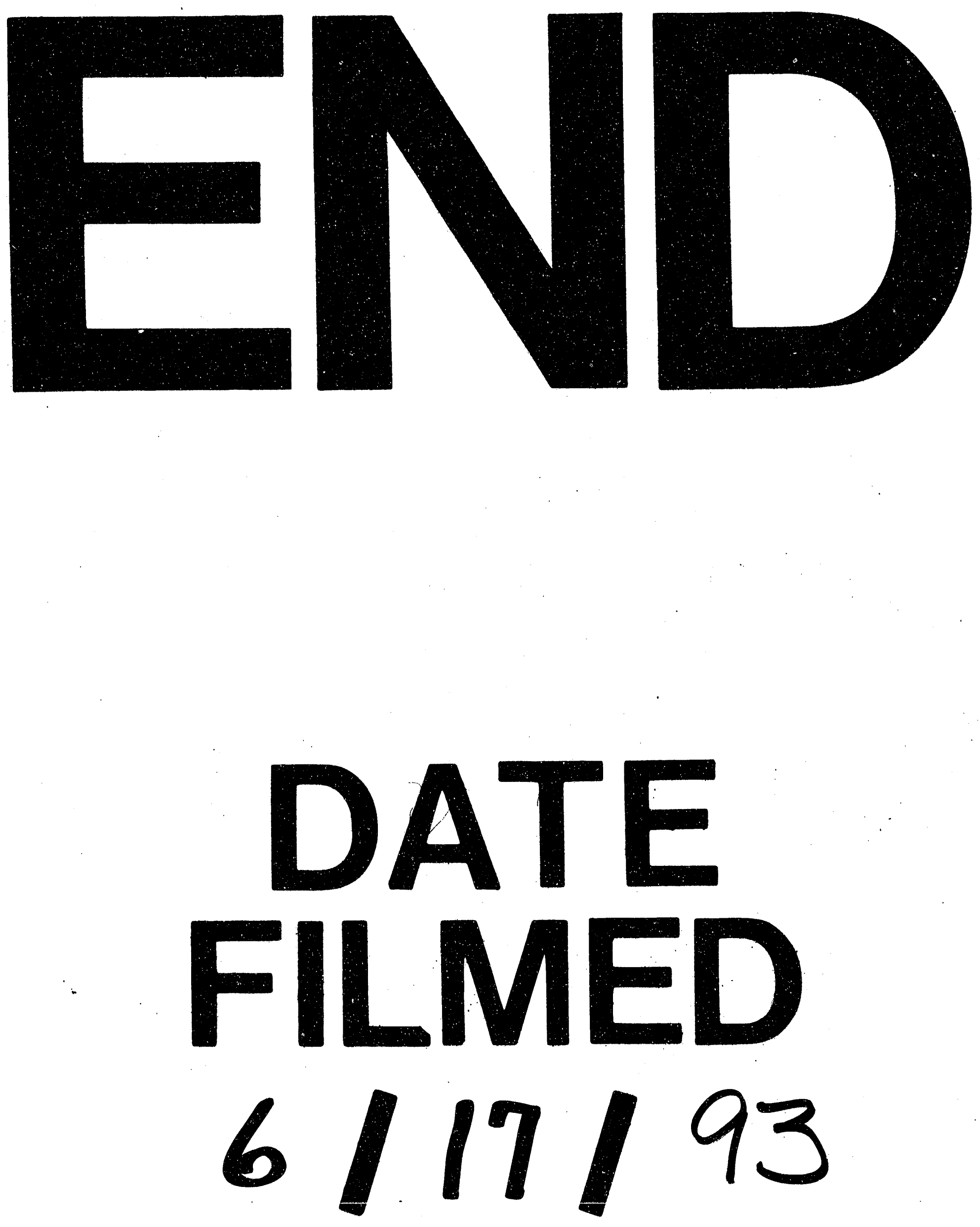
